\title{
Dynamics of Students' willingness to Communicate in English during an Online Discussion
}

Showat Achmad Ardiansyah ${ }^{1 *}$, Agus Wijayanto², Abdul Asib ${ }^{3}$

1,3 Universitas Sebelas Maret Surakarta, Indonesia

${ }^{2}$ Universitas Muhammyadiah Surakarta

Corresponding Author: Showat Achmad Ardiansyah E-mail: Showat_a87@student.uns.ac.id

ARTICLE INFO

Received: November 12, 2020

Accepted: December 14, 2020

Volume: 2

Issue: 5

DOI: $10.32996 /$ ijels.2020.2.5.2

\section{KEYWORDS}

Willingness to Communicate, $E F L$, Idiodynamic, Online group discussion.

\section{ABSTRACT}

A number of studies on WTC have applied various conversational contexts to gain a deeper understanding of students' WTC. However, there is no study reporting the dynamic nature of one's WTC during an online oral group discussion. Accordingly, the present study attempted to contribute to the literature of WTC by examining the students' WTC during an online group discussion. Applying idiodynamic case study, six English-majoring students were recruited. The findings showed that the dynamics of students' WTC was constructed by psychological, conversational, and linguistic aspects. The use of the internet as the mediator of communication was also found to influence one's WTC in either positive or negative directions. The analysis showed that the direction of influence of internet on one's WTC was accounted for by their self-confidence.

\section{Introduction}

An individual goes through a complex process and dynamics when deciding to speak, especially in second or foreigh language. One of the factors leading to this decision is individual difference called Willingness to Communicate. In the field of second language acquisition, Willingness to Communicate (L2WTC) is a notion used to explain one's readiness to engage in communication with other individuals using a L2 (Macintyre, Dornyei, Clement, \& Noels, 1998).

As Macintyre et al.'s (1998) call on viewing WTC as a situational variable that changes over time, many studies examine the dynamic nature of WTC. A number of communication contexts are applied to gain deeper understanding of one's WTC, such as dyadic conversation (e.g., Kang, 2005, Macintyre \& Legatto, 2011) and group setting (e.g., Pawlak, Mystkowska-Wiertelak, \& Bielak, 2016). Studies on WTC applies different method to understand its dynamic nature, qualitative, quantitative, and the combination of both.

In studying the dynamic nature of WTC, Macintyre and Legatto (2011) developed idiodynamic method, by combining a computer-based WTC self-rating software and stimulated recall interview, this method is specifically developed to study the dynamic nature of psychological aspect in communication, such as WTC. However. Despite the significant contribution this method offers, only few studies were reported to apply this method. Another attempt in examining the nature of WTC was made by Mystkowska-Wiertelak and Pawlak (2014) by asking the participants of their study to note their level of WTC every thirty second during a conversation.

Previous studies revealed that type of interaction (i.e, dyadic, group, or whole-classroom interaction) influence one's level of WTC (e.g Cao \& Philp, 2006; Ilter, 2018). However, In examining the dynamics of WTC, the majority of existing studies asked their participants to involve in an offline dyadic conversation (e.g. Macintyre \& Legatto, 2011; Mystkowska-Wiertelak \& Pawlak, 2014; Nematizadeh \& Wood, 2019; Shirvan \& Talebzadeh, 2017; Wood, 2016) and whole-classroom interaction (e.g Pawlak et

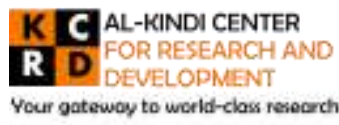

Published by Al-KindiCenter for Research and Development. Copyright (c) the author(s). This is an open access article under CC BY license (https://creativecommons.org/licenses/by/4.0/) 
al., 2016). Despite the significant contributions previous studies provide to the body of literature, it is important to note that most of them applies dyadic conversation where the researchers or their associates give questions and the participants response to them. It is quite different from the nature of group discussion, where every member of the discussion possesses complete freedom to either ask questions or state opinions.

Considering that type of interactions have different nature and influence one's WTC, studies on dynamics of WTC in a small group setting is still scarce. Moreover, with the increasing popularity of internet-mediated communication, there is a notable gap related to the dynamics of one's WTC in an online communication. The present study attempts to fill this gap of knowledge by examining the dynamics of WTC in an online small group discussion. Accordingly, the following research questions are proposed:

1) How does EFL students' WTC fluctuates in an online oral group discussion ?

2) What are the underlying factors of the fluctuation of their WTC?

\section{Literature Review}

Since MacIntyre et al. (1998) argued that WTC in L2 should be viewed as a dynamic,situation-specific variable rather than a trait-like variable, researchers begin to examine the fluctuating nature of WTC. Using quantitative, qualitative, and mixedmethod approaches. A number of studies have significantly contributed to the deeper understanding of WTC as a situationspecific variable that fluctuates over time following a range of psychological, contextual, or linguistic factors.

In Kang's (2005) qualitative study on dynamic emergence of students WTC, four Korean male students engaged in dyadic conversations with English native speakers. Each conversation lasted for one hour. Based on the conversations, these students reported a number of factors affecting their WTC during a conversation. The study concluded that WTC is "an individual's volitional inclination towards actively engaging in the act of communication in a specific situation, which can vary according to interlocutor(s), topic, and conversational context, among other potential situational variables (p.291)".

Another attempt in viewing the dynamic nature of WTC was conducted by Maclntyre and Legatto (2011). They developed what so-called as "idiodynamic method", this method was specifically developed to see the fluctuation of one's psychological aspect during a conversation, including WTC. The study involved six female students to perform a number of instructions. Since the conversation was analogous to oral examination, vocabulary recall was the most influential factors in affecting the participants WTC, in addition to language anxiety.

In the effort to see the pattern of fluctuations of EFL students WTC during a conversation, Pawlak \& Mystkowska-Wiertelak (2015) asked eight Polish EFL students to perform a 10-minute dialog in pairs. In this study, they were asked to note their level of WTC every thirty seconds when hearing a beep. The study found that a number of factors, such as topic, planning time, cooperation and familiarity with the interlocutor, the opportunity to express one's ideas, the mastery of requisite lexis, the presence of the researcher, and individual variables underlie the students WTC.

One's WTC is associated with fluency, as Wood's (2016) idiodynamic study revealed. In this study, four Japanese EFL students were asked to perform a brief talk with a Canadian who remain silent during the conversation and gave only non-verbal responses. The study revealed the interrelationship between speech fluency and WTC, where non-fluency may result in lower level of WTC, and vice versa.

\section{Methodology}

Prior to data collection, a preliminary survey was conducted by distributing a WTC questionnaire $(\alpha=0.69)$ to a total of eightyfour English department students of a state university in Central Java, Indonesia. Based on their responses, six participants ( 3 male and 3 female students) were recruited. Each two of them represented low, moderate, and high level of trait-like WTC. They had studied English for approximately 8-10 years. They were 19-20 years of age when the study was conducted. Due to confidentiality, the participants' name is pseudonym.

Table 1. Participants' Demographic Information

\begin{tabular}{|c|c|c|c|c|}
\hline Name & Age & Gender & Length of Studying English & Trait-like WTC level \\
\hline Via & 20 & Female & $8-10$ years & Low \\
\hline
\end{tabular}




\begin{tabular}{|c|c|c|c|c|}
\hline Awan & 20 & Male & 8-10 years & Low \\
\hline Lita & 19 & Female & 8-10 years & Moderate \\
\hline Alan & 20 & Male & $8-10$ years & High \\
\hline Mia & 20 & Female & 8-10 years & High \\
\hline Rama & 21 & Male & $8-10$ years \\
\hline
\end{tabular}

In the present study, the data collection was conducted in online and offline settings. In the online phase, a thirty-minutes discussion was done through Zoom meeting application. Two topics were selected, namely "students' view of online learning" and "Covid-19= Economy or Health." Each topic was discussed for fifteen minutes. While the participants were quite familiar with the first topic because they had experienced it for last six months, the second topic was quite challenging. The difference in difficulty level was expected to create a fluctuation of WTC during the discussion. Different from previous studies where the participants are given a number of instructions, in the present study we only threw the general topics and gave a complete freedom to the participants to talk or not to talk during the discussion.

The second phase of the data collection was done in offline setting. Once the online discussion ended, the participants were invited to go to the campus and self-rate their WTC using Anion Variable Tester 2.0. This software, developed by Maclntyre and Legatto (2011), allowed the participants to rate their level of WTC while watching the record of the discussion by clicking a computer mouse. After finishing the self-rating phase, the graph showing participants' ups and downs of WTC was printed. The printed graph was then used as a basis to conduct the stimulated recall interview. The interview was conducted in Bahasa Indonesia.

\section{Results}

During a 30-minutes discussion, participants reported fluctuating WTC. This fluctuation was accounted for by a number of factors. The individual analysis of each participants' rise and drop of WTC are presented below.

Via

Via's trait-like WTC in English in a discussion, based on the preliminary survey, was categorized as low. however, throughout the online discussion, fluctuations of WTC were reported.

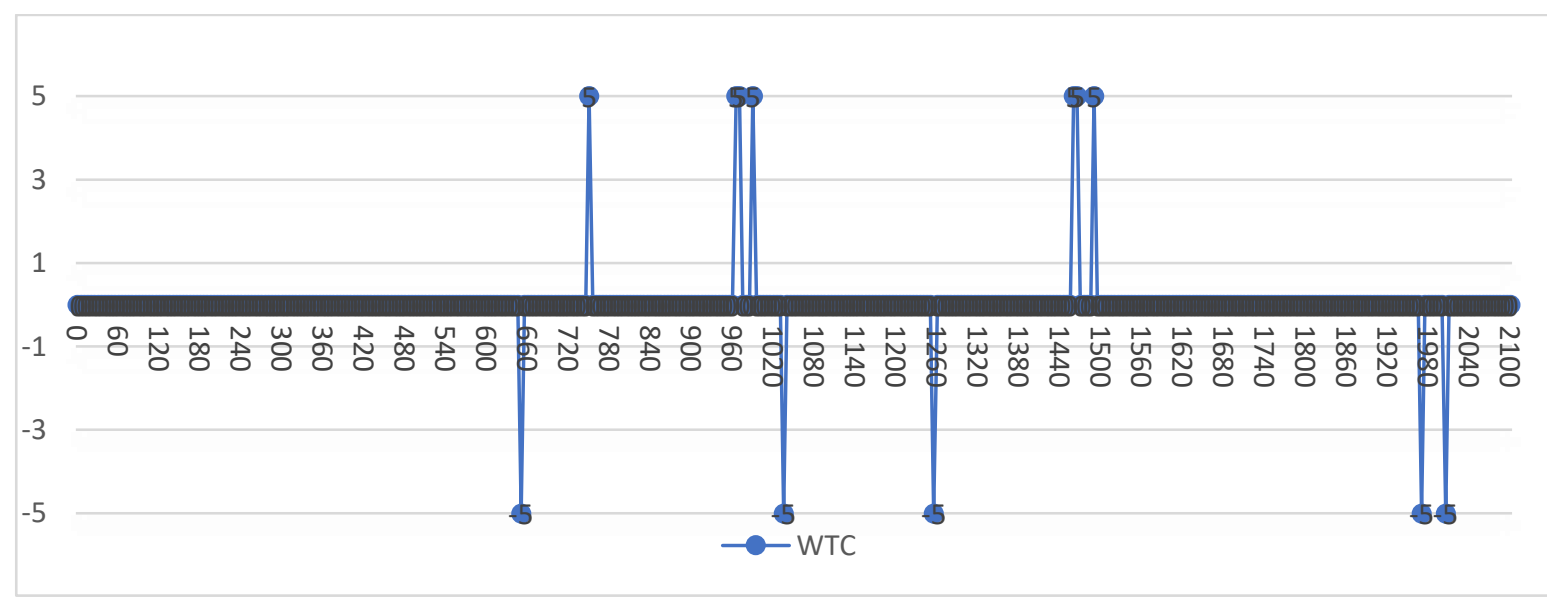

Figure 1. Via's WTC during 30-minutes online discussion

For Via, it took ten minutes to engage in the discussion. In the first ten minutes, Via kept silent as she preferred to wait for others' opinion, she said that during that time, she focused on "building sentences" in her head, striving for finding approp riate vocabularies for her argument and collecting her confidence.

"So I prefer listening to them first, what they are talking about while thinking about the vocabularies and gathering my confidence, that is why I always become the last person to talk.."

It was revealed that the drop of her WTC was caused by technological issues, where she could not hear her friends clearly due to poor connection. However, after a momentary drop at second 651, she reported a rising WTC at around second-750, this 
rise was reported after all members of the discussion state their opinions. She stated that she had gathered enough confidence to talk. She argued though she had no problem with her listening skill, she found it difficult to produce the language.

Starting from second-1020 (around minute-17), the discussion moved to the second topic. Via's psychological journey in this topic was begun by a drop of WTC. She said that the topic was actually easy for her if it was discussed in Bahasa Indonesia, she again asserted that vocabulary significantly affected her WTC because she did not have enough vocabulary to talk about "Covid19: Health or Economy?" using English. With regard to the second valley of WTC (second-1255) in the second topic, vocabulary was still a great barrier for her WTC. She failed to find appropriate English response for Rama's argument about "corona has no cure.". However, after approximately eight minutes of silence and dropped WTC, she reported a rise of WTC during second1465 until 1490. During this moment, she responded to the topic and said that she agreed with her friends' opinion. She said that during that time, she had gathered all of her confidence to speak. At the end of the discussion, the valley (second-1970 until 2005) was accounted for by poor signal that prevented her from listening to the discussion clearly. Accordingly, she was less willing to speak because she did not have any idea about what her friends had talked about. To sum, Via's fluctuation of WTC was mainly caused by her lack of vocabulary, in addition to technological issue (i.e., poor internet signal).

Awan

Based on the preliminary survey, Awan's trait-like WTC was low. However, fluctuations of WTC were captured during a 30minutes online discussion.

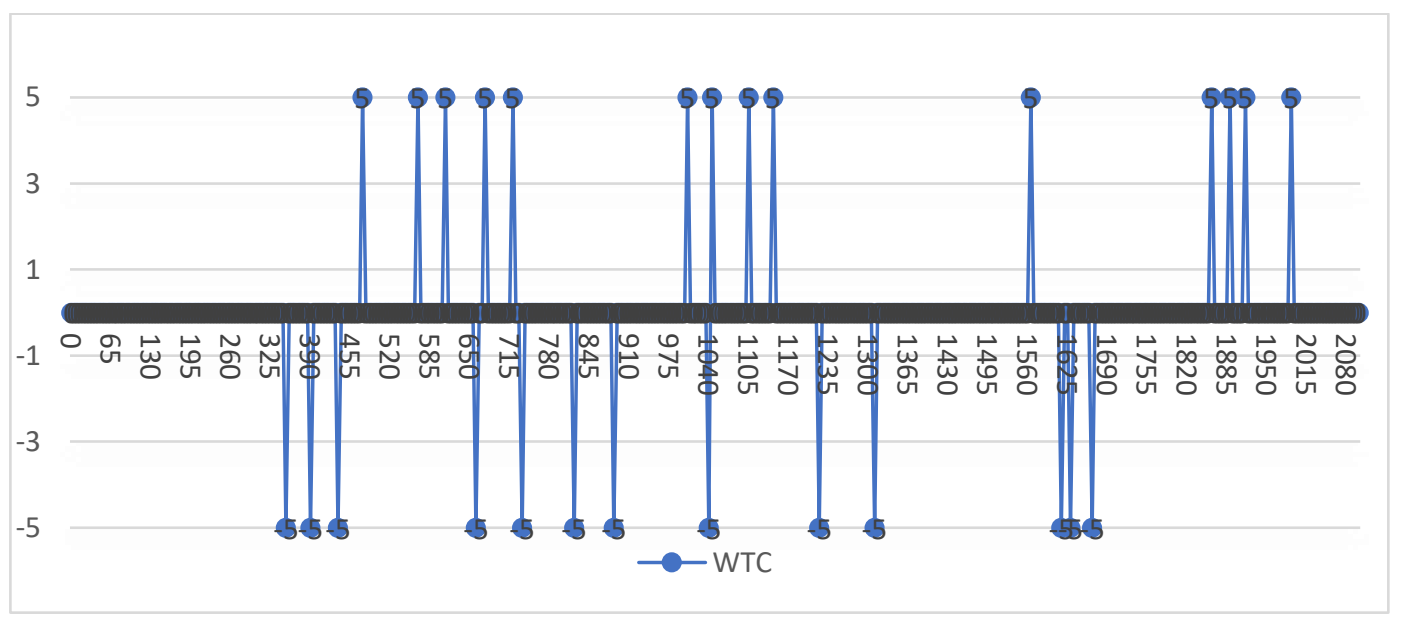

Figure 6. Awan's WTC during 30-minutes online discussion

Awan's WTC dropped at the beginning of the discussion (second 350-435). Based on the interview, this drop was caused by technological issues (disturbing sound), which made him panic and anxious. Besides, he said that at the beginning of the discussion, after Rama opened the discussion, his WTC began to rise (second 475-610) because he wanted to respond to Rama's argument. At that time, he talked about the disadvantages of online learning. However, after a series of rising WTC when stating his arguments, his WTC dropped (second-660), this momentary drop was accounted for by his confidence as he said that he was afraid about his friends' perception of his speech, particularly related to his pronunciation. In addition, he also did not have anything to said at that moment because he had poured out all of his ideas before. Fifteen seconds after the drop, his WTC rose again when he thought that he possessed ideas to respond to Rama's argument about the advantage of online learning. This rise also did not last long, at around second 820 his WTC dropped again because the video was lagging due to poor internet connection, which made him panic. At around second-1000, everyone was silent, during this time, Awan reported a rise of WTC and thrown a joke about the attendance list. When confirmed during the interview, he said "what happens if no one starts talking...." In addition, he also had previous experience related to the joke, which increased his WTC at that moment.

Different from Via who responded to the second topic with a drop of WTC, Awan reported a rising WTC when the discussion moved to the second topic (second-1040). This rise was accounted for by his knowledge related to the topic, he said that the topic was popular during the pandemic and he had a number of ideas to speak about the topic. Unfortunately, this rise immediately dropped because Rama took the chance to be the first to speak about this topic. He said that although he had an idea to talk, he still waited for Rama to finish his speech. However, during this waiting, he was afraid that the idea began to "fade" if he did not speak immediately. Once Rama finished his talk, Awan began to speak about his idea related to the topic, 
which reflected his high WTC around second-1045 to 1145. Around the second 1220-1310, the discussion was about which one should be prioritized between health and economy during the pandemic. During this time, Awan's WTC dropped because his thought is already similar to his friend's opinion. He argued that it was not necessary to speak about the same thing twice.

At around second-1565, his WTC rose again. During that time, they were talking about the "blessing" of the Covid-19 pandemic for them. Awan said that his WTC rose because he had an authentic experience related to this topic. However, it was followed by a series of drops (second-1630 to 1665) due to disturbing noises from the application. His WTC journey during this discussion was ended with a series of rising WTC (second 1890-1990). During that time, the discussion was about using Zoom for online learning. Based on the recall interview, he stated that his WTC rose because he had the knowledge related to that topic, as he explained about the data package spent on each lecturing session.

To conclude, the factors underlying Awan's fluctuating WTC during 30 minutes- discussion covers confidence, topic-related knowledge, technological issues. Confidence leads to Awan's WTC when he had topic-related knowledge, and vice versa. His concern about pronunciation also lower his confidence for a moment, which results in a drop in WTC. Awan's WTC also dropped after he stated his thought because he did not have anything to say anymore. The technological issues (i.e., disturbing noises, lagging due to poor connection) also leads to Awan's drop of WTC.

Lita

Following the result of the preliminary survey, Lita's trait-like WTC during a discussion was categorized as moderate. During the 30-minutes online discussion through Zoom application, the graph showed a stable rise of Lita's WTC. She did not indicate any drop of WTC throughout the discussion. The interview revealed that in general, her WTC rise because she had been familiar with the topic, in addition, she also had known her interlocutors because they were classmates.

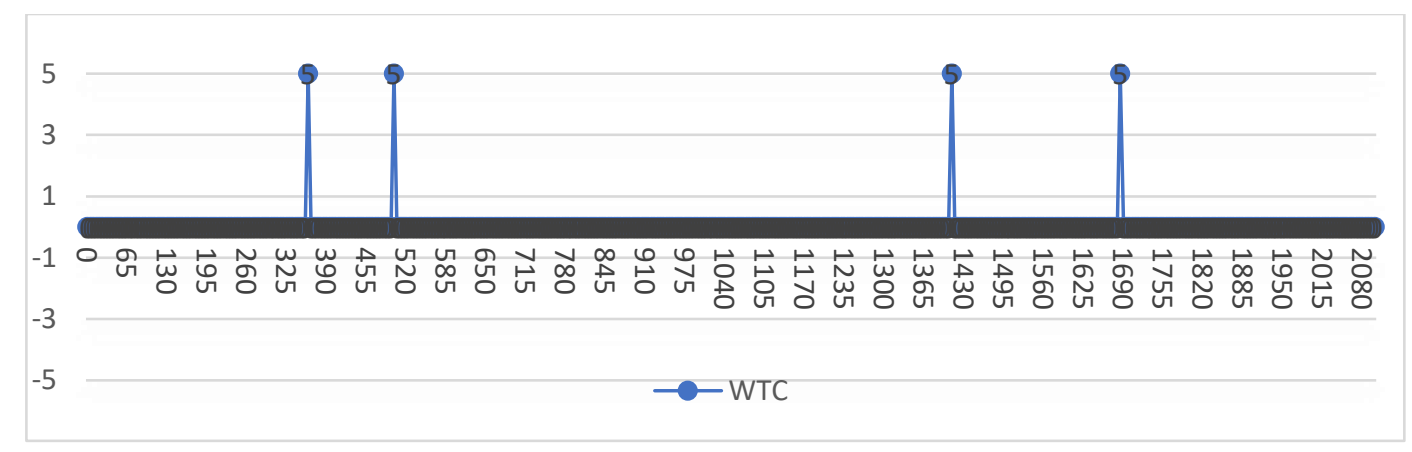

Figure 7. Lita's WTC during 30-minutes online discussion

The first rise of WTC was reported at around second 360, at that time, she was talking about the advantage of online learning after Rama and Mia asked for her opinion about the topic. Besides having topic-related knowledge, knowing that her friends have similar ideas to hers also enhances her WTC at that moment. The next rise of WTC was reported around second-500, she talked about the disadvantage of online learning. She said that this rise because she had an experience related to the topic. The next rise was reported around second-1410 when the members of the discussion talked about whether the economy or health should be prioritized during the pandemic. This rise was accounted for by her topic-related knowledge, where she had a different point of view from their friends. The last peak of WTC was reported around second-1685. According to Lita, her WTC rise because she could not hear Alan's argument due to disturbing noises, accordingly, she asked Alan to repeat his argument.

To conclude, Lita's high WTC throughout the discussion was accounted for by topic-related knowledge, confidence, and motivation. The latter occurs when she asked Alan to repeat his arguments due to a poor connection that prevents her from listening to him clearly.

\section{Alan}

Following his response on questionnaire distributed during preliminary study, Alan's WTC was categorized as moderate. During the discussion, he reported a number of rises and drops of WTC due to a number of factors. 


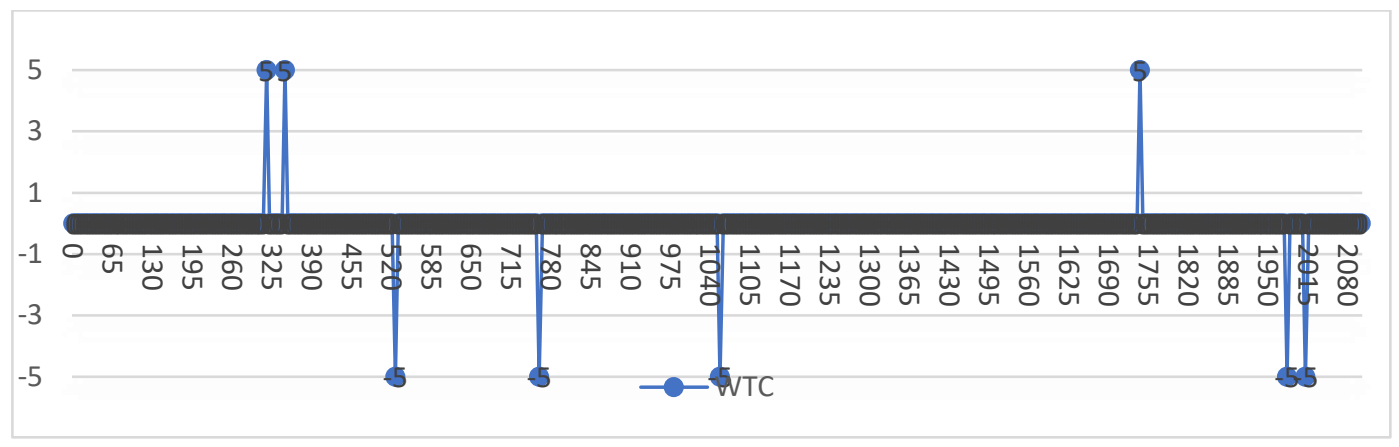

Figure 8. Alan's WTC during 30-minutes online discussion

Alan reported his first rise of WTC around second-315 to 345, he explains that his WTC rose because his friends agree with his opinions, which enhanced his WTC. However, the rise was followed by a series of dropped WTC, as shown in second-525, his WTC dropped because his thoughts have been presented by other persons and he did not think it is necessary to talk the same thing twice. This drop was followed by another drop at around second-760. Around this time, there was a momentary silence because no one was speaking. This condition makes Alan's WTC drop because he did not have enough confidence to open a conversation, besides he also did not have any idea to talk in order to break this silence.

When the second topic began, he reported a drop of WTC (second 1055). Regarding this drop, he said that he did not have any idea about the topic. In addition to the lack of topic-related knowledge that made him kept silent, poor connection also worsened his WTC, as he said:

"...., besides there were disturbing noises, it prevents me from hearing their speech clearly..."

After discussing “Covid-19: Health or Economy?", which depleted Alan's WTC and silenced him for approximately ten minutes, A rise of WTC was noted around 1740 when they discussed the blessing of the pandemic. Based on the interview, Alan's WTC rose because he had an experience related to the topic. However, this rise was followed by a series of drops until the end of the discussion, which is indicated in second-1980 to2010. The first drop was caused by disagreements expressed by other participants of the discussion. At that moment, he was arguing that he could save money during the pandemic, which triggered Mia to ask further about how to save money during pandemic. After explaining how to save money from his point of view and experience, it turns out that his friends could not hear his explanation clearly due to poor connection, which accounts for his second drop of WTC. In addition, he said that he was not willing to talk anymore after knowing that no participants agreed with his argument. In conclusion, Alan's fluctuating WTC during the discussion was accounted for by interlocutors' response (agreement/disagreement), atmosphere, confidence, and technological issues.

Rama

Rama's trait-like WTC was categorized as high based on the questionnaire in preliminary study. During the 30-minutes discussion, Rama was the first person who opened the discussion. Throughout the discussion, he acted like a moderator of the discussion as he stated his opinions and asked for other opinions.

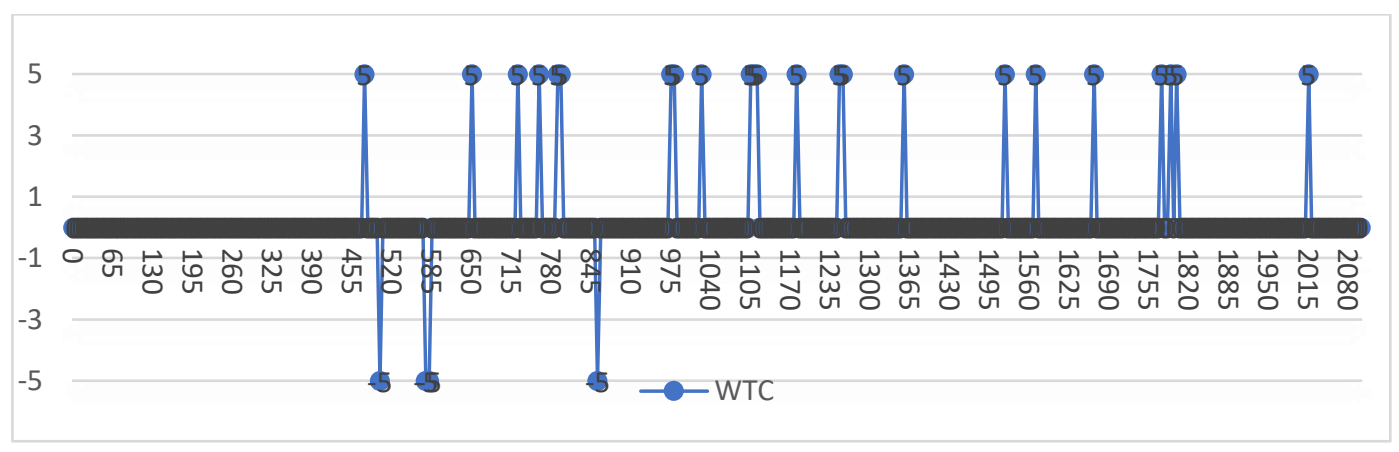

Figure 9. Rama's WTC during 30-minutes online discussion 
The first rise of WTC was reported to occur in second-475. His WTC rose because he considered the topic interesting, besides, other participants" silence triggered his "sense of responsibility" to start the discussion. However, this WTC did not last long as drops of WTC were reported (second-500 and 580). These drops were accounted for by lack of vocabulary and poor structure, as he said:

"Indeed, I am poor in structure, that explains the drop. I need longer times to think about the words"

However, he managed to cope with his vocabulary problems and reported a series of rising WTC around second-650 to 795. During the interview, he said that although he was not confident with his limited linguistic skill (i.e structure and vocabulary), he said that he was still willing to communicate in English to maintain his confidence. He said that the condition would be worse for him if he stopped speaking, as he said:

"I would be "blank" If I stopped speaking, like I can't do anything, can't choose words, don't know what to say, so I keep speaking with my limited vocabularies, using words I know"

After succeeded to maintain a series of rising WTC, his WTC dropped due to vocabulary problems. Besides, the presence of a person who was not his classmates, Via, also affected his WTC. He stated that Via's presence made him think twice before speaking. The atmosphere of the discussion also affected Rama's WTC, as reported in the graph in second-980. He said:

"The atmosphere was fun; it improved my WTC"

When the discussion moved to the second topic, he reported a series of rising WTC (second 1025 to 1355). However, these peaks of WTC do not necessarily mean that he enjoyed his speech all the time as he said that disturbing noises made him uncomfortable, though it did not affect his WTC:

"Those noises disturbed my focus and made me uncomfortable when speaking"

His positive WTCs lasted until the end of the discussion, when talking about the "blessing" of the Covid-19 pandemic, spikes of WTC were reported (second 1520 -1665) because he was interested in the topic. Around second- 1800 to 1820, his WTC also rose when Alan made a "controversial" statement about saving during the pandemic. He said:

"I was responding to Mia's disagreement and everyone agreed..."

The last spike of WTC was reported when Awan explained about the data package spent during online learning using Zoom. His WTC rose because he had topic-related knowledge and experiences and wanted to add Awan's argument.

"I was excited, I experience that fact, it made me want to speak up.."

To sum up, Rama's WTC fluctuation during the discussion was caused by "sense of responsibility," linguistic factors (i.e., vocabulary and grammar), motivation, interlocutors' responses, atmosphere, and technological issues.

Mia

Mia's WTC was categorized as high. Throughout the discussion, her WTCs were mostly positive. She was the only one to express disagreement against the interlocutor's argument.

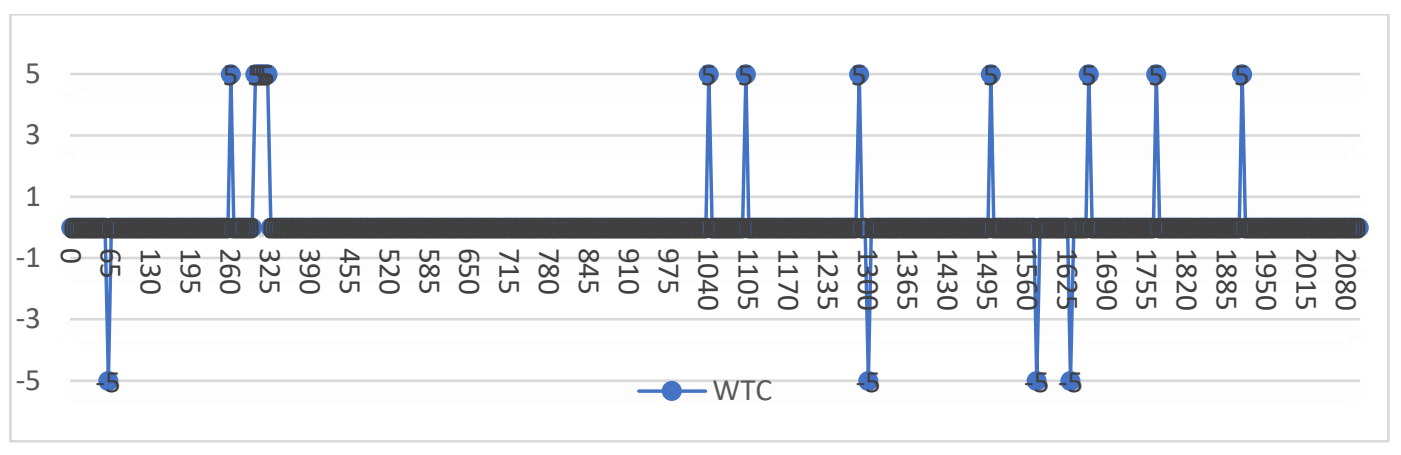

Figure 10. Mia's WTC during 30-minutes online discussion 
As shown in the graph, Mia's WTC dropped in the first minute (second-60) of the discussion, It dropped because she was afraid of making mistake, as she said:

"At the beginning, I was afraid to make a mistake, so I tend to keep silent and listening to others..."

Around second-260, a rise was reported. The recall interview revealed that her WTC rose because she had an idea related to the topic and was confident that her idea was right.

"I have an idea about this, I have a strong argument, it encourages me to speak, besides I am sure that my argument is correct"

It seems that Mia's concern about the correctness of her ideas continues, as a series of rising WTC was reported around second300 until 325. At that time, she supported Lita's argument about the disadvantages of online learning that makes student sleepy.

"I was talking, but not recorded, I was saying like "jujur banget sih Lita". My WTC increases because I also experience what Lita says and I agree if it is true."

When the discussion moved to the second topic, she reported a rise of WTC (second 1040). When confirmed during the interview, the rise actually represented the desire to communicate. It rose because she has already had an idea to talk about this topic, however, she did not speak due to a lack of confidence. as she said:

"I have read about the second topic. I was thinking about this topic while taking a bath this morning and "I will talk here", but again, I am not confident enough to be the first person"

The second rise of WTC represents actual speech (second-1100) when she expressed agreement with Rama's argument.

"I agree with his argument, and I add more opinion"

At around second-1300, a drop of WTC was reported. At that time, Lita was not talking fluently. Mia said she wanted to help her organize her sentences, but she canceled it as Lita managed to finish the speech well:

", I am confident because I know what Lita wants to say, I want to correct her but I let her find the vocabulary alone, honestly I want to directly take her turn. She seems to ask for help (to find words) but finally she made it..."

Another drop of WTC was also reported around second- 1575 to 1670 . This drop was caused by her lack of topic-related knowledge as she said:

"I have no idea, is there any "blessing" from this pandemic for us? I don't think so.."

After a series of drops due to lack of topic-related knowledge, she reported rising WTC when Alan made "controversial statement" about saving during pandemic.

"How could he save money? While we need many internet quotas, 2gb per day, while Campus subsidizes only fifty thousand rupiahs..". It is weird that he could save money.."

To sum up, Mia's WTC fluctuation during this 30-minutes online discussion was caused by confidence, topic-related knowledge, afraid of making mistake, and motivation.

\section{Discussion}

Underlying factors of WTC revealed in this study could be categorized into three groups, namely psychological, conversational, and linguistic factors. The psychological factors found in the present study covers confidence, responsibility and motivation, while conversational factors cover topic familiarity, interlocutors, technological issues, and atmosphere. The linguistic factors affecting participants' WTC in this study were lack of vocabulary.

Discussion on WTC as a situational variable takes perspective from Dynamic System Theory (De Bot, Lowie, \& Verspoor, 2007). This theory views that language can be seen as a dynamic system, i.e., a set of variables that interact over time (p.7). This study, consistent with previous studies ( e.g. Cao, 2011; Fadilah, 2018; Fallah, 2014), found that self-confidence serves as one of factors influencing one's WTC. Having adequate confidence may promote one's WTC, while lacking of it may decrease one's WTC. However, every individual possesses a different threshold of confidence to start a speech. As shown in this study, while Via obliged herself to have a structured, organized sentence before speaking, Rama still felt confident despite his limited vocabulary and less structured sentence due to poor grammar. Self-confidence is not a stand-alone variable to establish one's WTC. Instead, it is co-constructed by other variables such as motivation, interlocutor response, among others. This study revealed the interaction between motivation and confidence in building one's WTC. In this study, motivation to avoid worse conditions (e.g., silence, blank), as reported by Rama, was found to promote WTC.

In the present study, contextual factors, defined as factors involved in immediate communication context (Cao, 2009), covers topic familiarity, interlocutors, technological issues, and atmosphere. The finding of this study is consistent with previous studies showing that topic familiarity affects one's WTC (e.g Cao \& Philp, 2006; Kang, 2005). However, it was revealed that lack 
of topic familiarity does not necessarily leads to silence or unwillingness to communicate. When it is combined with sense of curiosity, it may result in willingness to communicate in the form of asking questions to the members of discussion.

The difference between online and offline communication is that the former involves a mediator of communication, in this case, is the internet. This mediator (i.e., internet) may serve as either driver or barrier of one's WTC. It serves as a barrier when it prevents individuals from listening to interlocutors' opinions, which eventually hinders them from responding to their interlocutors in the form of, for instance, responding to arguments, disagreeing with interlocutor opinions, or even adding more information related to the interlocutors' argument. However, with an adequate level of confidence, technological issues (e.g., disturbing noises or video lag due to poor connection) may promote one's willingness to engage in communication in the form of asking questions or clarifications.

Consistent with previous studies' finding on the effect of interlocutor participation (Cao \& Philp, 2006; Shirvan, Khajavy, MacIntyre, \& Taherian, 2019), the interlocutor response during a discussion also influence one's WTC. However, the effect can be either positive or negative. During a discussion, individuals' WTC may increase when the interlocutors support or agree with their argument. Indeed, an agreement or support from interlocutor(s) can enhance one's self-confidence, which eventually leads to an increase in WTC. In contrast, interlocutors' disagreement or curiosity related to individuals' opinion may debilitate their WTC, let alone when the individuals possess low self-confidence or linguistic proficiency that makes them difficult to provide further information or clarification related to the argument, as shown by Alan when Mia was asking for his clarification regarding his opinions.

Atmosphere of a discussion also influence one's WTC, as found in this study and existing literature of WTC(Yashima, Maclntyre, \& Ikeda, 2018). During a discussion where every member of discussion is free to remain silent or initiate communication, a "period of silence" possibly occurs when their ideas "run out." This period of silence, when everyone is busy to find a topicrelevant opinion within their head, may result in an anxiety-triggering atmosphere and eventually decrease one's WTC. Such an atmosphere may serve as either barrier or driver of one's WTC. Along with a sense of responsibility to trigger a discussion, this atmosphere may promote one's WTC, as shown by Awan, by throwing a joke related to the topic to "break the ice." In contrast, this atmosphere may further deplete one's WTC when he or she lacks self-confidence and topic-related knowledge, as reported by Alan.

In L2 communication, even a seemingly fun atmosphere may decrease one's WTC. A joke thrown by a member of discussion may decrease another member's WTC when he or she faces linguistic problems. As reported by Via, during the discussion, she failed to transform her desire to communicate into WTC behavior when Awan attempted to break the silence with his jokes due to her lack of vocabulary, preventing her from giving appropriate responses.

\section{Conclusion}

The present study confirmed the dynamic and unique nature of WTC in a group discussion. In a discussion where everyone is free to take roles to either asking questions or responding to questions or opinions, one's WTC may fluctuate as a result of the interaction between psychological, contextual, and linguistic factors. When communication is mediated by technology, the mediator may result in either a positive or negative effect on one's WTC. Positive and negative effects of technological issues on one's WTC are the result of the interaction between a range of factors of one's WTC.

Considering the unique and dynamic nature of WTC, it seems that there is no "one-size-fits-all" solution to enhance one's WTC, let alone for EFL students with limited opportunities to use the target language, as in the Indonesian EFL context. When dealing with classroom context or linguistic issues that affect students' WTC, teachers are recommended to create an anxiety-free by taking the students' linguistic proficiency into account. Finding a topic familiar with the students may also enhance the students' WTC, as indicated by previous studies. However, when it deals with individuals' personality, which is quite stable and not situation-specific, a collaboration with the institution's counselor or psychologist could be helpful in assisting students build their self-confidence, which eventually affects their WTC during communication using English. An experimental, collaborative study between the language and psychology field may open a new avenue of research to address the students' low level of WTC due to lack of self-confidence.

Funding: This research received no external funding.

Conflicts of Interest: The authors declare no conflict of interest. 


\section{References}

[1] Cao, Y. (2009). An ecological view of situational willingness to communicate in asecond language classroom. In H. Chen \& K. Cruickshank (Eds.),Making adifference: Challenges for applied linguistics(pp. 199-218). Newcastle-upon-Tyne,England: Cambridge Scholars Press

[2] Cao, Y. (2011). Investigating situational willingness to communicate within second language classrooms from an ecological perspective. System, 39(4), 468-479. https://doi.org/10.1016/j.system.2011.10.016

[3] Cao, Y., \& Philp, J. (2006). Interactional context and willingness to communicate: A comparison of behavior in whole class, group and dyadic interaction. System, 34(4), 480-493. https://doi.org/10.1016/j.system.2006.05.002

[4] De Bot, K., Lowie, W., \& Verspoor, M. (2007). A dynamic systems theory approach to second language acquisition. Bilingualism, 10(1), 7-21. https://doi.org/10.1017/S1366728906002732

[5] Fadilah, E. (2018). Willingness to Communicate from Indonesian Learners' Perspective: A Dynamic Complex System Theory. Journal of ELT Research, 3(2), 168-185. https://doi.org/10.22236/JER

[6] Fallah, N. (2014). Willingness to communicate in English, communication self-confidence, motivation, shyness and teacher immediacy among Iranian English-major undergraduates: A structural equation modeling approach. Learning and Individual Differences, 30, 140147. https://doi.org/10.1016/j.lindif.2013.12.006

[7] Ilter, O. (2018). Turkish EFL Learners' Willingness to COmmunicate: Promoting and Debilitating Sides of Teacher Effect. Erzincan Üniversitesi Sosyal Bilimler Enstitüsü Dergisi (ERZSOSDE), 9(2), 14-29.

[8] Kang, S.-J. (2005). Dynamic emergence of situational willingness to communicate in a second language. System, 33, $277-292$. https://doi.org/10.1016/j.system.2004.10.004

[9] Macintyre, P. D., Dornyei, Z., Clement, R., \& Noels, K. A. (1998). Conceptualizing Willingness to Communicate in a L2: A Situational Model of L2 Confidence and Affiliation. The Modern Language Journal, 82(IV), 545-562. https://doi.org/10.1111/j.15404781.1998.tb05543.x

[10] Macintyre, P. D., \& Legatto, J. J. (2011). A dynamic system approach to willingness to communicate: Developing an idiodynamic method to capture rapidly changing affect. Applied Linguistics, 32(2), 149-171. https://doi.org/10.1093/applin/amq037

[11] Mystkowska-Wiertelak, A., \& Pawlak, M. (2014). Fluctuations in learners' willingness to communicate during communicative task performance: Conditions and tendencies. Research in Language, 12(3), 245-260. https://doi.org/10.2478/rela-2014-0019

[12] Nematizadeh, S., \& Wood, D. (2019). Willingness to communicate and second language speech fluency: An investigation of affective and cognitive dynamics. Canadian Modern Language Review, 75(3), 197-215. https://doi.org/10.3138/cmlr.2017-0146

[13] Pawlak, M., \& Mystkowska-Wiertelak, A. (2015). Investigating the dynamic nature of L2 willingness to communicate. System, 50, 1-9. https://doi.org/10.1016/j.system.2015.02.001

[14] Pawlak, M., Mystkowska-Wiertelak, A., \& Bielak, J. (2016). Investigating the nature of classroom willingness to communicate (WTC): A micro-perspective. Language Teaching Research, 20(5), 654-671. https://doi.org/10.1177/1362168815609615

[15] Shirvan, M. E., Khajavy, G. H., MacIntyre, P. D., \& Taherian, T. (2019). A Meta-analysis of L2 Willingness to Communicate and its Three High-evidence Correlates View project. Journal of Psycholinguistic Research, 1-9. https://doi.org/10.3968/j.css.1923669720110706.030

[16] Shirvan, M. E., \& Talebzadeh, N. (2017). English as a foreign language learners' anxiety and interlocutors' status and familiarity: An idiodynamic perspective. Polish Psychological Bulletin, 48(4), 489-503. https://doi.org/10.1515/ppb-2017-0056

[17] Slimani, S. (2018). The Impact of the Willingness to Communicate on EFL Learners 'Speaking Performance inside the Classroom : The Case of Third Year LMD Students of English Dedications To the soul of my parents, To my lovely sisters Sarah and Dounia, To the one I love and. 8 MAI 1945 UNIVERSITY.

[18] Wood, D. (2016). Willingness to communicate and second language speech fluency: An idiodynamic investigation. System, 60, 11-28. https://doi.org/10.1016/j.system.2016.05.003

[19] Yashima, T., Maclntyre, P. D., \& Ikeda, M. (2018). Situated willingness to communicate in an L2: Interplay of individual characteristics and context. Language Teaching Research, 22(1), 115-137. https://doi.org/10.1177/1362168816657851

[20] Yu, M. (2015). An examination of the dynamic feature of WTC through dyadic group interaction. System, 55, 11-20.

https://doi.org/10.1016/j.system.2015.08.001 